\title{
Optical Microscopy, X-Ray Diffraction, and Dielectric Permittivity Studies in Binary Mixtures of Nematogens Showing Induced Smectic Phase
}

\author{
Suchismita Datta Sarkar ${ }^{1,2}$ and Basana Choudhury ${ }^{2}$ \\ ${ }^{1}$ Department of Physics, Karimganj College, Karimganj 788710, India \\ ${ }^{2}$ Department of Physics, NIT Silchar, Silchar 788010, India \\ Correspondence should be addressed to Basana Choudhury, basana_choudhury@rediffmail.com
}

Received 9 April 2011; Accepted 27 May 2011

Academic Editor: Ali Hussain Reshak

Copyright (C) 2011 S. Datta Sarkar and B. Choudhury. This is an open access article distributed under the Creative Commons Attribution License, which permits unrestricted use, distribution, and reproduction in any medium, provided the original work is properly cited.

\begin{abstract}
The binary mixtures of nematogenic compounds 4-n-pentyl phenyl 4-n'-hexyloxy benzoate (ME6O.5) and 4-cyanophenyl 4heptyl benzoate (CPHB) show the presence of induced smectic phase. In the present paper we report the phase diagram of the binary system (ME6O.5+CPHB) obtained by polarizing optical microscopy as well as the results of X-ray diffraction and static dielectric permittivity measurements on the system throughout the entire composition range. The observed variation of dielectric anisotropy with molar concentration in the induced smectic phase region is explained by assuming molecular associations in the mixture which is supported by our measurements of layer spacing in the induced smectic phase by X-ray diffraction studies.
\end{abstract}

\section{Introduction}

There is special interest in understanding the behaviour of liquid crystalline mixtures, so that better materials may be produced for applications [1]. One of the unusual aspects of the binary liquid crystalline mixtures is the formation of smectic phase, called the induced smectic phase, from the components which do not themselves show smectic phase in their pure state [2-10]. Though exceptions are there $[11,12]$, induced smectic phases form easily when a polar molecule of electron-acceptor type given in Scheme 1, where a terminal substituent $\mathrm{Y}$ can be $-\mathrm{CN},-\mathrm{NO}_{2},-\mathrm{CHO},-\mathrm{NCS}$, $-\mathrm{CF}_{3},-\mathrm{OCF}_{3},-\mathrm{Cl},-\mathrm{COCH}_{3},-\mathrm{COR}$, and $-\mathrm{NO}_{2} ; \mathrm{R}$ is $\mathrm{H}_{2 n+1} \mathrm{C}_{n}-, \mathrm{H}_{2 n+1} \mathrm{C}_{n}-\mathrm{O}-$, and $\mathrm{H}_{2 n+1} \mathrm{C}_{n}-\mathrm{NH}-$; the bridge group $\mathrm{Z}$ is $-\mathrm{COO}-,-\mathrm{N}=\mathrm{N}-,-\mathrm{N}(\mathrm{O})=\mathrm{N}-,-\mathrm{CH}=\mathrm{N}-,-\mathrm{C} \equiv \mathrm{C}-$, $-\mathrm{HC}=\mathrm{CH}-$, single bond; $n=0,1,2$, is mixed with nonor low polar electron-donor type of molecule with the molecular structure same as above and with $\mathrm{Y}$ as $\mathrm{H}_{2 n+1} \mathrm{C}_{n}$, $\mathrm{H}_{2 n+1} \mathrm{C}_{n}-\mathrm{O}-, \mathrm{H}_{2} \mathrm{~N}-, \mathrm{H}_{2 n+1} \mathrm{C}_{n}-\mathrm{NH}-, \mathrm{R}, \mathrm{Z} ; n$ have the same meaning as the polar molecules and $n$ cannot be simultaneously equal to zero for both components. Induced smectic phase is usually observed when $\operatorname{ring}(\mathrm{s}) \mathrm{A}$ are benzene or heteroaromatic ones and also with cycloalkane rings [13]. Maximum stability of the induced phase usually occurs for nearly equal concentrations of the two components $[3,4,14]$. The polarity of the end group, core structure, and overall length of the molecules have pronounced influence on the phase induction phenomena [9].

We have obtained induced smectic phase in a new binary mixture of nematogenic compounds 4-n-pentyl phenyl 4$\mathrm{n}^{\prime}$-hexyloxy benzoate (ME6O.5) and 4-cyanophenyl 4-heptyl benzoate (CPHB). To understand the unusual behaviour of this system we have studied the trends of different physical parameters with molar concentration.

\section{Experimental}

The compounds ME6O.5 and CPHB were purchased from AWAT Co. Ltd., Warsaw, Poland, and were used without further purification. The chemical names, structural formulae, and transition temperatures of the pure compounds are as in Schemes 2 and 3. 


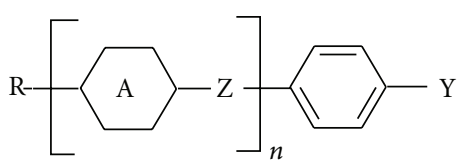

SCHeme 1

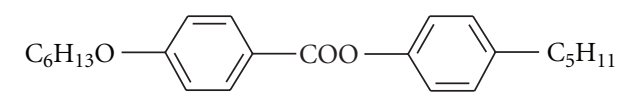

$$
\text { Solid } \frac{49.5^{\circ} \mathrm{C}}{35.5^{\circ} \mathrm{C}} \text { Nematic } \frac{62.5^{\circ} \mathrm{C}}{62.2^{\circ} \mathrm{C}} \text { Isotropic }
$$

Scheme 2: Component 1: 4-n-pentyl phenyl 4-n'-hexyloxy benzoate (ME6O.5).

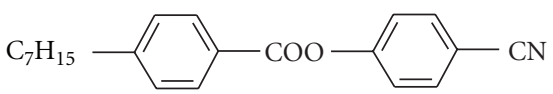

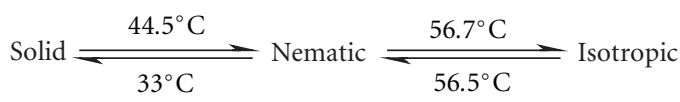

Scheme 3: Component 2: 4-cyanophenyl 4'-n-heptyl benzoate (CPHB).

Eight mixtures of (ME6O.5+CPHB) with mole-fractions of CPHB equal to $0.18,0.22,0.26,0.32,0.50,0.54,0.59$, and 0.76 were prepared.

Phase diagram of the binary system (ME6O.5+CPHB) was constructed by observing textures of the pure samples as well as their mixtures under a Leica Make DMLP polarizing microscope equipped with a Linkam hot stage LTSE-350 with TMS 94 temperature programmer. The samples were heated/cooled at a rate of $1^{\circ} \mathrm{C} / \mathrm{min}$. The values of transition temperatures were confirmed by differential scanning calorimetric (DSC) studies.

The experimental work of X-ray diffraction studies was performed by using an experimental set-up at the Department of Physics, North Bengal University [15]. X-ray diffraction patterns were recorded photographically on a flat plate camera using $\mathrm{CuK}_{\alpha}$ radiation of wavelength $\lambda=1.542 \AA$ at $5^{\circ} \mathrm{C}$ below the nematic-smectic transition temperature $\left(T=T_{\mathrm{NS}}-5\right)$ for five mixtures exhibiting induced smectic phase with unaligned samples. Temperatures were measured and regulated with a precision temperature controller. The $\mathrm{X}$-ray diffraction photographs were digitized by a scanner. The Origin 7 software was used for data analysis purpose.

The dielectric permittivities $\left(\varepsilon_{\|}\right.$and $\left.\varepsilon_{\perp}\right)$ were measured by a digital LCR bridge (HIOKI 3522-50 LCR HiTESTER) at frequency $10 \mathrm{kHz}$. The frequency $10 \mathrm{kHz}$ is low enough to allow measurements of essentially the static permittivities and high enough to prevent electrochemical reactions or the formation of double layers at the electrodes. The liquid crystal samples were filled in glass cells in isotropic state by capillary action and then sealed. Each cell was consisted of

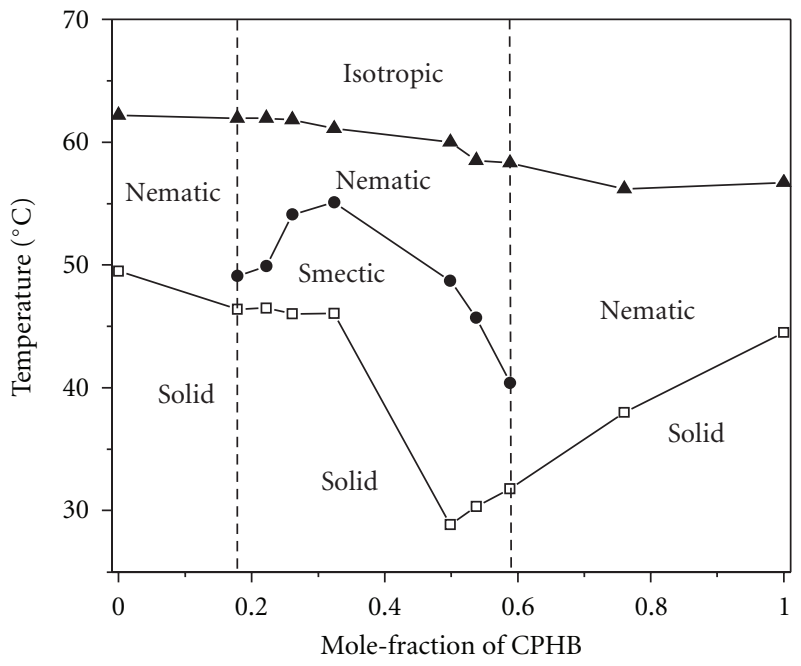

FIGURE 1: Phase diagram for the binary system of ME6O.5+CPHB. $\Delta$ isotropic-nematic transition temperature, - nematic-smectic A transition temperature, and $\square$ melting temperature.

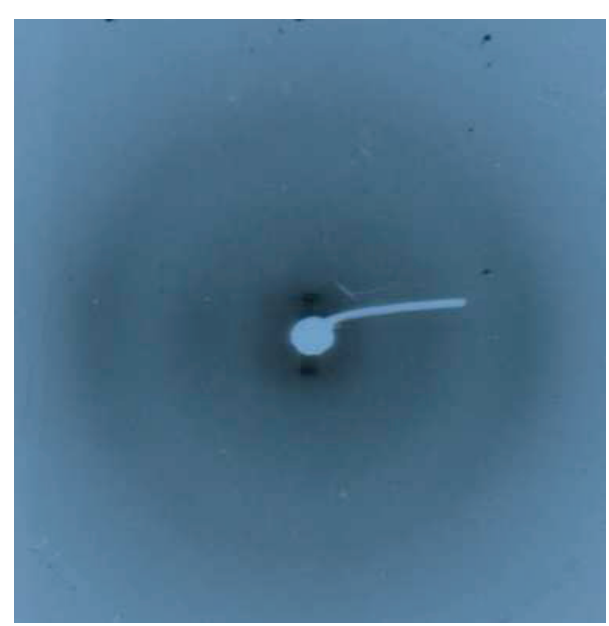

Figure 2: X-ray diffraction photograph of mixture for unaligned sample at $T_{\mathrm{NS}}-5^{\circ} \mathrm{C}$ with $x=0.18$.

two plane parallel Indium Tin Oxide (ITO)-coated glass plates which had inside polymer-coating for homogeneous alignment of the sample. The homogeneous alignment of the samples gave the dielectric component $\varepsilon_{\perp}$. The homeotropic alignment of the samples was obtained by applying electric field above threshold voltages $\left(V_{\mathrm{th}}\right)$ of the samples which gave the other component $\varepsilon_{\|}$. All the data were recorded during cooling of the sample. The thickness of the samples was $\sim 5 \mu \mathrm{m}$. To obtain the temperature variation of dielectric permittivities the cells were put in a thermostated block fabricated by us whose temperature was controlled to $\pm 0.5^{\circ} \mathrm{C}$. The bridge voltage across the sample was maintained sufficiently low $(\sim 0.3 \mathrm{~V})$ to prevent electric field induced instabilities. For the standardization of the apparatus, 4-pentyl-4' -cyanobiphenyl (5CB) and 4-pentyloxy-4' cyanobiphenyl (5OCB) were used. 


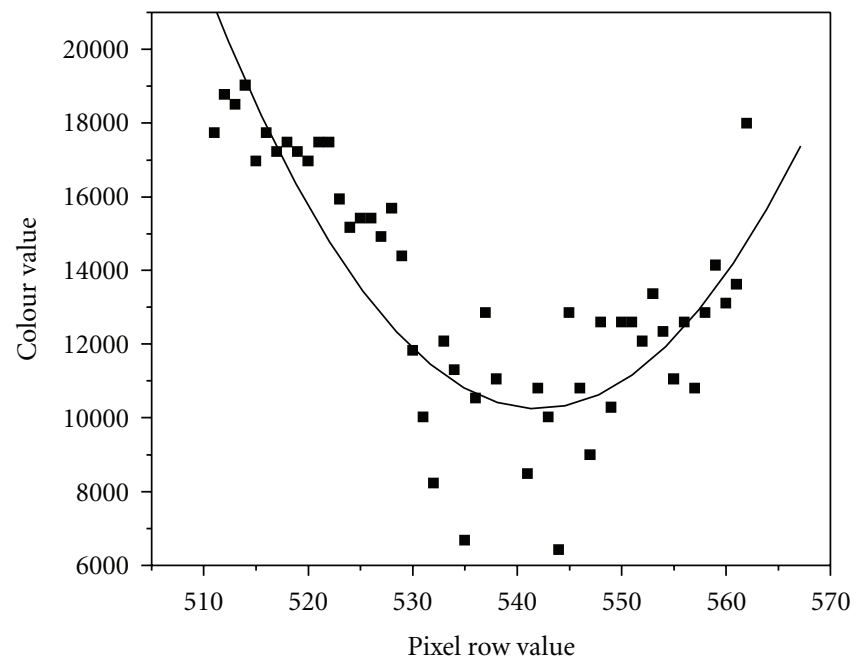

(a)

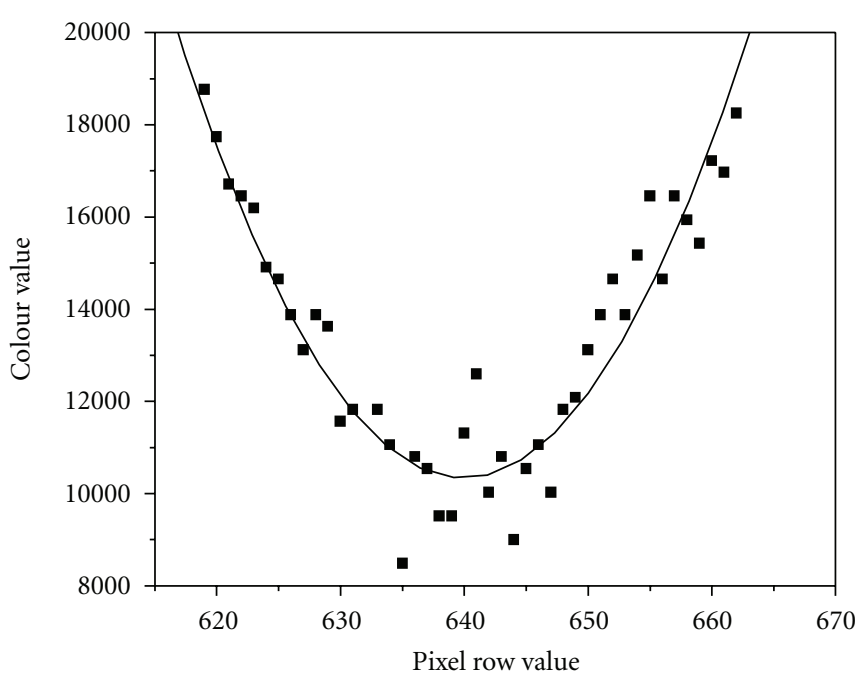

(b)

FIGURE 3: Fitted curves for locating the peaks to find the "d" value for mixture with $x=0.18$ at $T=T_{\mathrm{NS}}-5^{\circ} \mathrm{C}$ : (a) lower inner crescent, and (b) upper inner crescent.

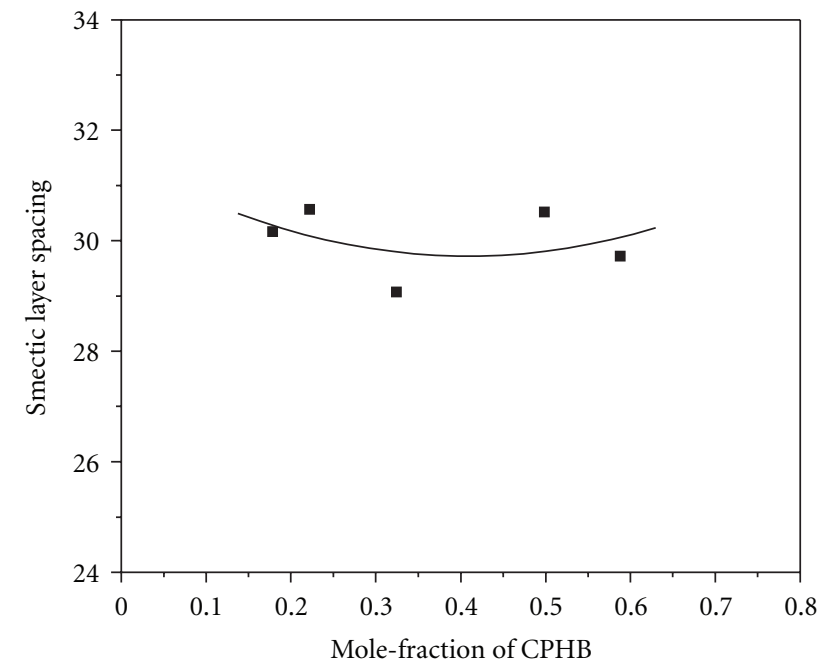

FIGURE 4: Variation of smectic layer spacing with mole-fraction of CPHB.

\section{Results and Discussion}

3.1. Texture Study. The phase diagram of the binary system (ME6O.5+CPHB) as obtained from the texture and DSC study is shown in Figure 1. The system shows enantiotropic induced smectic phase in the range $0.18 \leq x \leq 0.59$, where $x$ is the mole-fraction of CPHB. Maximum thermal stability of the induced smectic phase is observed at $x \approx 0.32$. Textures of the mixtures in induced smectic phases are either focal conic or fan shaped.

3.2. X-Ray Diffraction Study. Representative XRD photograph in the smectic phase for the mixture with $x=0.18$ using unaligned sample is shown in Figure 2. Layer spacing (d) values were obtained from the inner meridional arc by using Bragg equation $2 d \sin \theta=\lambda$. The photographs were digitized by a scanner and the peak positions were determined by fitting pixel colour values obtained from meridional scan. Representative fitted curves for locating the peaks for the mixture with $x=0.18$ are shown in Figure 3 .

In Figure 4, we have plotted the variation of layer spacing with mole-fraction of CPHB in deep smectic phase $(T=$ $\left.T_{\mathrm{NS}}-5^{\circ} \mathrm{C}\right)$. Smectic layer spacing shows minima around $x \approx 0.32$. The model molecular length of pure compounds CPHB and ME6O.5 in their most extended configuration, as obtained from a molecular model kit, is $21.0 \AA$ and $24.4 \AA$, respectively. Since the layer spacing in all the mixtures is greater than the model molecular lengths of the pure compounds, so there is possibility of formation of molecular association. Such possibility was also proposed earlier [16, 17].

3.3. Dielectric Study. Temperature dependence of the dielectric permittivities $\left(\varepsilon_{\|}\right.$and $\left.\varepsilon_{\perp}\right)$ of the pure compounds as well as the binary mixtures of (ME6O.5+CPHB) is shown in Figure 5.

All the mixtures and the pure compounds exhibit positive dielectric anisotropy $(\Delta \varepsilon)$, which is large for pure $\mathrm{CPHB}$ molecules (A) due to the terminal polar $\mathrm{CN}$ group and very small for nonpolar ME6O.5 molecules (B). The variation of dielectric anisotropy with mole-fraction of $\mathrm{CPHB}$ at $\mathrm{T}=T_{\mathrm{NS}}-5^{\circ} \mathrm{C}$ is shown in Figure 6 . The observed variation of dielectric anisotropy with molar concentration in the smectic phases deviates from linearity indicating the presence of homo- and heterodimers in the mixtures. This behaviour is in accordance with the other similar systems (ME6O.5+CPPCC(p-cyanophenyl trans-4pentyl cyclohexane carboxylate)) and (ME5O.5(4-n-pentyl phenyl 4-n' -pentyloxy benzoate) $+5 \mathrm{CB}$ ) [18]. For calculating 


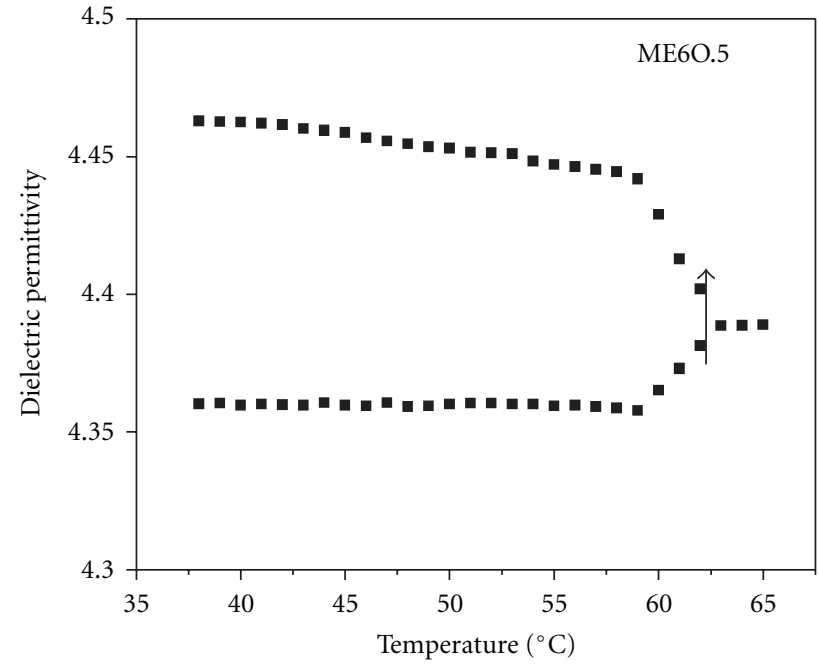

(a)

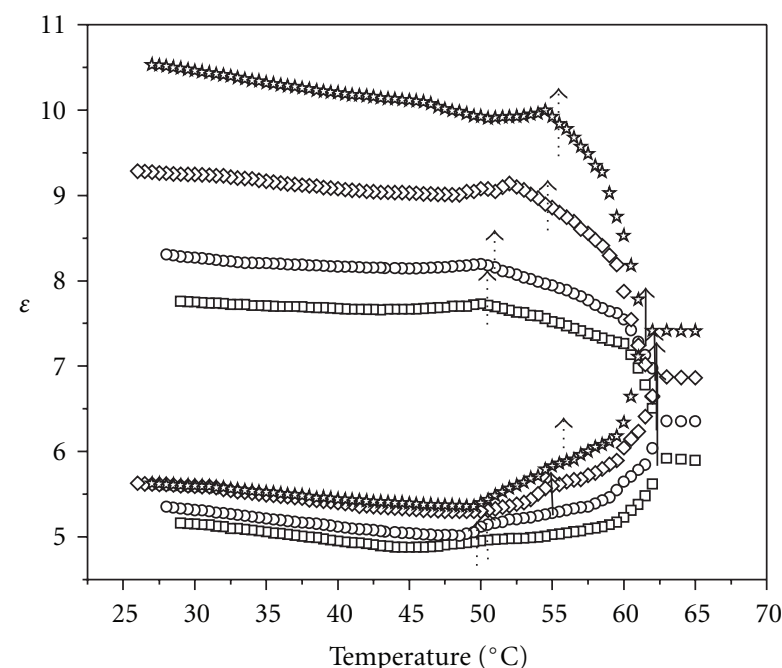

ㅁ $x=0.18$

○ $x=0.22$

$$
\diamond x=0.26
$$$$
\text { \& } x=0.32
$$

(c)

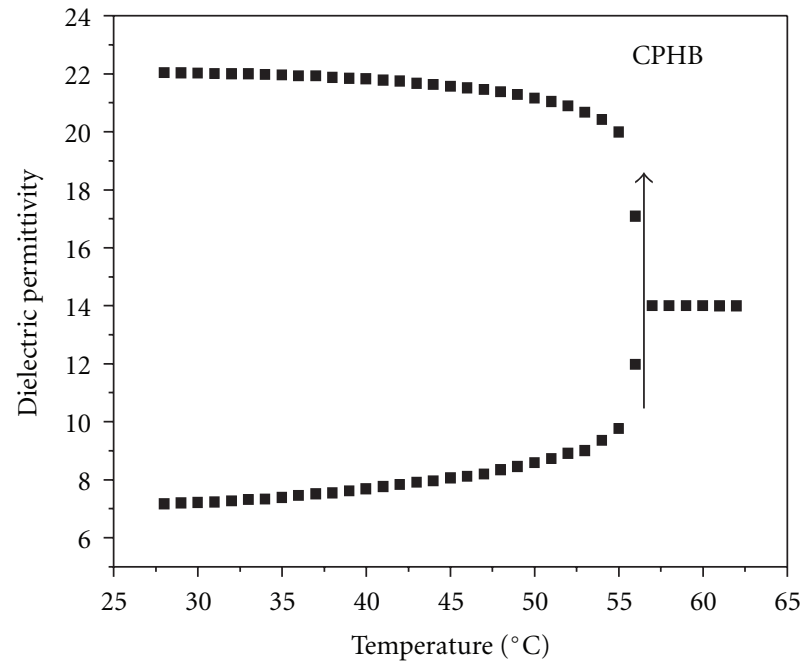

(b)

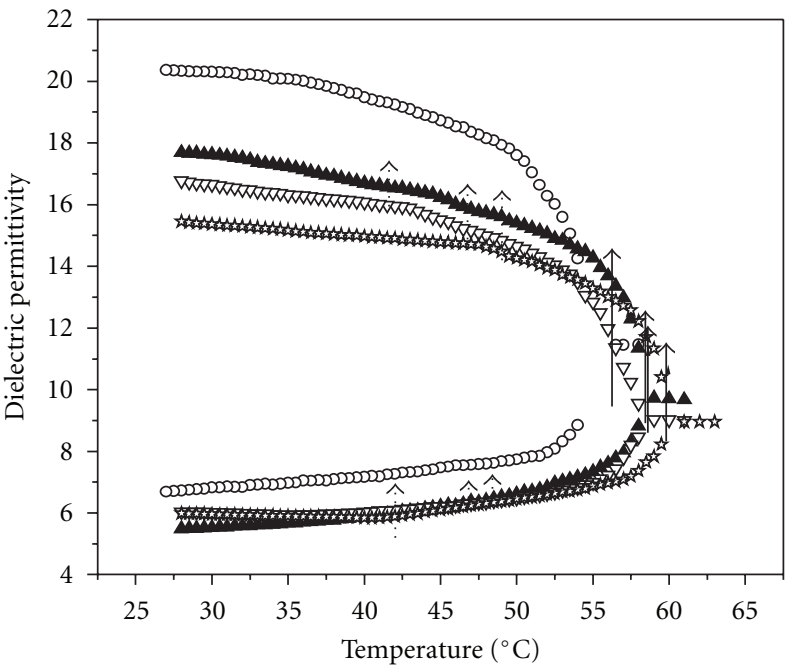

$$
\begin{array}{ll}
\circ x=0.76 & \nabla x=0.54 \\
\triangle x=0.59 & \text { } x=0.5
\end{array}
$$

(d)

FIGURE 5: Temperature variation of dielectric permittivities of (a) and (b) pure compounds and (c) and (d) their mixtures. Up arrow indicates isotropic to nematic transition, and dotted arrow indicates nematic to smectic transition.

the variation of dielectric anisotropy $(\Delta \varepsilon)$ with mole-fraction of $\mathrm{CPHB}$, we assume that in the mixture $\mathrm{A}, \mathrm{B}, \mathrm{AA}$, and $\mathrm{AB}$ types of molecules are in equilibrium. This assumption is based on the information gathered from XRD studies that the polar molecule $\mathrm{CPHB}$ can form association whereas the nonpolar one ME6O. 5 cannot form association in their pure state. The mole-fraction of different species, $x_{\mathrm{A}}, x_{\mathrm{B}}, x_{\mathrm{AA}}$, and $x_{\mathrm{AB}}$, can be determined from the equilibrium constants $K_{\mathrm{AA}}$ and $K_{\mathrm{AB}}$ for the associations $\mathrm{A}+\mathrm{A} \leftrightarrow \mathrm{AA}, \mathrm{A}+\mathrm{B} \leftrightarrow \mathrm{AB}$, respectively. Using $K_{\mathrm{AA}}=1000$ and $K_{\mathrm{AB}}=850$, we have calculated the mole-fraction of different species. These values of $K_{\mathrm{AA}}$ and $K_{\mathrm{AB}}$ are typical of similar systems, studied previously [19]. Figure 7 depicts the mole-fraction of different monomers and dimers as function of the mole-fraction of
CPHB. It is clear from Figure 7 that the concentration of polar molecule up to $x \approx 0.74$, heterodimers predominate over homodimers.

The values of $\Delta \varepsilon$ may be written as

$$
\Delta \varepsilon=x_{\mathrm{A}} \Delta \varepsilon_{\mathrm{A}}+x_{\mathrm{AA}} \Delta \varepsilon_{\mathrm{AA}}+x_{\mathrm{AB}} \Delta \varepsilon_{\mathrm{AB}}+x_{\mathrm{B}} \Delta \varepsilon_{\mathrm{B}} .
$$

In pure $\mathrm{CPHB}$, the calculated mole-fraction of dimer is 0.969 . So here we assume that $\Delta \varepsilon_{\mathrm{AA}} \approx$ the experimentally measured value of $\Delta \varepsilon$ for CPHB at respective temperatures. Since $\Delta \varepsilon_{\mathrm{A}}$ cannot be calculated, we assume $\Delta \varepsilon_{\mathrm{A}} \approx \Delta \varepsilon_{\mathrm{AA}}$. Since no dimer formation is exhibited by ME6O.5 in its pure state, as evident from X-ray diffraction study, we can take $\Delta \varepsilon_{\mathrm{B}}$ to be equal the experimentally measured value of $\Delta \varepsilon$ for ME6O.5 at respective temperatures. We estimated $\Delta \varepsilon_{\mathrm{AB}}$ from 


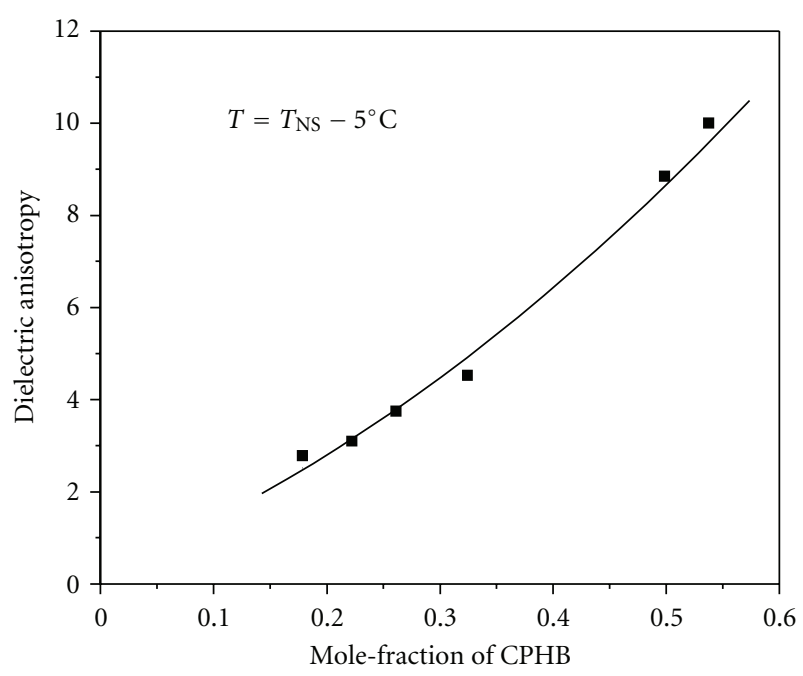

FIgURE 6: Variation of dielectric anisotropy with mole-fraction of CPHB at $T=T_{\mathrm{NS}}-5^{\circ} \mathrm{C}$. represents experimental values; solid line represents calculated values.

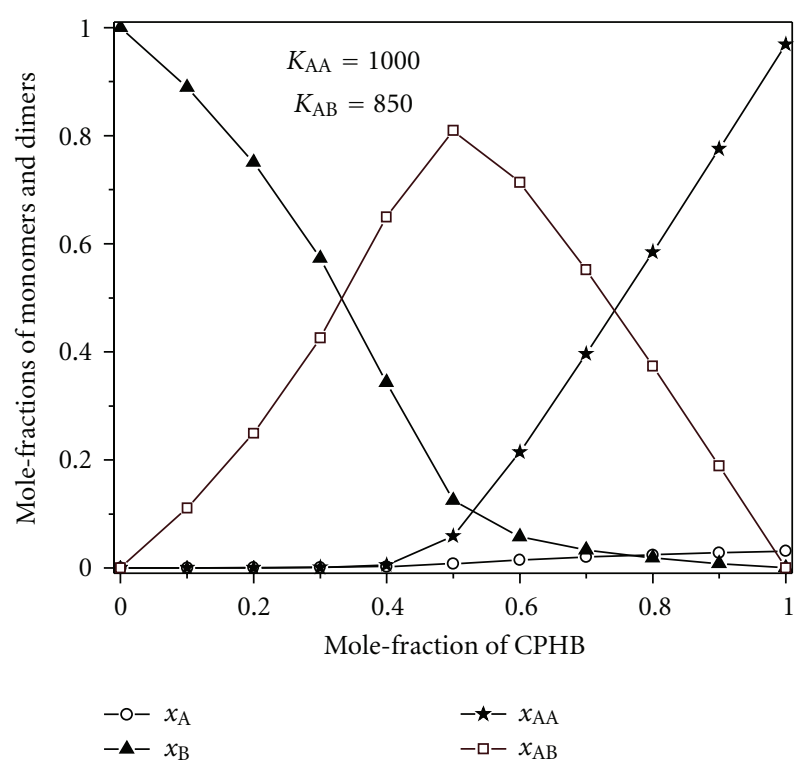

Figure 7: Mole-fraction of different monomers and dimers with mole-fraction of CPHB.

the experimentally measured value of $\Delta \varepsilon$ at $T=T_{\mathrm{NS}}-5^{\circ} \mathrm{C}$ for the mixure with equimolar concentration by substituting the other known values in (1). We have calculated $\Delta \varepsilon$ at $T=T_{\mathrm{NS}}-5^{\circ} \mathrm{C}$ from (1) by using known values of different parameters. From Figure 6, it is seen that the nature of variation of calculated values of dielectric anisotropy is in good agreement with that of experimental values of dielectric anisotropy.

\section{Conclusion}

The polar-nonpolar binary system (ME6O.5+CPHB) exhibits enantiotropic induced smectic phase in the region
$0.18 \leq x \leq 0.59$. Maximum thermal stability of the induced smectic phase is observed at $x \approx 0.32$. The variation of dielectric anisotropy with mole-fraction of CPHB deviates from linearity. This behaviour can be explained by assuming the formation of molecular association in the mixtures, which is qualitatively supported by our XRD measurements.

\section{Acknowledgments}

The authors are grateful to Dr. W. Piecek, Wojskowa Akademia Techniczna, Warszawa, Poland, for his kind donation of dielectric cells used in this work. They are thankful to Professor P. K. Mandal, North Bengal University, India, for kindly permitting them to use the experimental set-up for XRD study at NBU. One of the authors (S. D. Sarkar) is thankful to the U.G.C., New Delhi, India, for the award of a teacher fellowship.

\section{References}

[1] D. A. Dunmur, R. G. Walker, and P. Palffy-Muhoray, "The physical properties of an ester/biphenyl mixture exhibiting an injected smectic phase molecular crystals and liquid crystals ," Molecular Crystals and Liquid Crystals, vol. 122, pp. 321-338, 1985.

[2] J. W. Park, C. S. Bak, and M. M. Labes, "Effects of molecular complexing on the properties of binary nematic liquid crystal mixtures," Journal of the American Chemical Society, vol. 97, no. 15, pp. 4398-4400, 1975.

[3] Z. Raszewski, "Dielectric studies of binary liquid-crystalline mixtures ," Liquid Crystals, vol. 3, no. 3, pp. 307-322, 1988.

[4] R. Dabrowski, J. A. Janik, J. M. Janik, and K. Otnes, "A neutron scattering study of dimerization and pairing of molecules in liquid crystal mixtures," Liquid Crystals, vol. 3, no. 4, pp. 443$452,1988$.

[5] N. K. Sharma, "Effect of alkyl chain length on EDA-complex formation in binary alkylamino-biphenyls and 4-nitrophenyl-4' -n-pentyloxy-cinnamate systems," Crystal Research and Technology, vol. 22, no. 4, pp. K63-K66, 1987.

[6] L. Songsheng, G. Jezhen, and W. Liangyu, "Induced smectic phase in binary systems containing alkyl cyano phenylcyclohexane," Molecular Crystals and Liquid Crystals, vol. 100, no. 3-4, pp. 285-297, 1983.

[7] G. Pelzl, U. Böttger, S. Diele, and D. Demus, "Induced $S_{A}$ phases in binary systems with EDA complexing," Crystal Research and Technology, vol. 22, no. 10, pp. 1321-1331, 1987.

[8] M. K. Das and R. Paul, "Optical birefringence, density and order parameter of an ester-biphenyl mixture exhibiting an injected smectic phase," Phase Transitions, vol. 46, no. 3, pp. 185-197, 1994.

[9] B. R. Jaishi and P. K. Mandal, "Optical microscopy, DSC and $\mathrm{X}$-ray diffraction studies in binary mixtures of 4-pentyloxy4'-cyanobiphenyl with three 4,4'-di(alkoxy) azoxybenzenes," Liquid Crystals, vol. 33, no. 7, pp. 753-765, 2006.

[10] P. D. Roy, A. Prasad, and M. K. Das, " Study of the physical properties of a mesogenic mixture showing induced smectic $\mathrm{A}_{d}$ phase by refractive index, density and x-ray diffraction," Journal of Physics Condensed Matter, vol. 21, no. 7, Article ID 075106, 2009.

[11] S. Datta Sarkar and B. Choudhury, "Study of refractive indices, density and order parameters of two nematogens and their 
eutectic mixture," Acta Physica Polonica A, vol. 118, no. 4, pp. 665-669, 2010.

[12] S. Giri, P. Manual, and S. Paul, "Study of physical properties of binary mixtures of two nematogens," Molecular Crystals and Liquid Crystals Science and Technology Section A, vol. 365, pp. 711-719, 2001.

[13] R. Dabrowski and K. Czuprynski, "Induced smectic and nematic phases and re-entrant phenomena," in Modern Topics in Liquid Crystals from Neutron Scattering to Ferroelectricity, A. Buka, Ed., World Scientific, London, UK, 1993.

[14] D. A. Dunmur, S. P. Farnan, and C. L. Murray, "Dielectric relaxation in coexisting nematic and smectic B phases," Liquid Crystals, vol. 19, no. 6, pp. 779-783, 1995.

[15] B. Bhattacharjee, S. Paul, and R. Paul, "Order parameter and the orientational distribution function for 4-cyanophenyl-4'n-heptyl benzoate in the nematic phase," Molecular Physics, vol. 44, no. 6, pp. 1391-1396, 1981.

[16] A. C. Rauch, S. Garg, and D. T. Jacobs, "Phase transitions in a nematic binary mixture," Journal of Chemical Physics, vol. 116, no. 5, pp. 2213-2218, 2002.

[17] T. Kyu, H. W. Chiu, and T. Kajiyama, "Induced smectic phase in a nematic liquid crystal mixture," Physical Review E, vol. 55, no. 7105, p. 7110, 1997.

[18] P. D. Roy, S. Paul, and M. K. Das, "Dielectric permittivity studies of nematogenic compounds and their binary mixtures showing induced smectic $A_{d}$ phase," Phase Transitions, vol. 79, no. 4-5, pp. 323-330, 2006.

[19] M. K. Das and R. Paul, "Calculation of layer thickness in smectic a phase of binary mixtures of terminal polar + terminal non polar mesogens," Molecular Crystals and Liquid Crystals Science and Technology Section A, vol. 260, no. 1, pp. 477-482, 1995. 

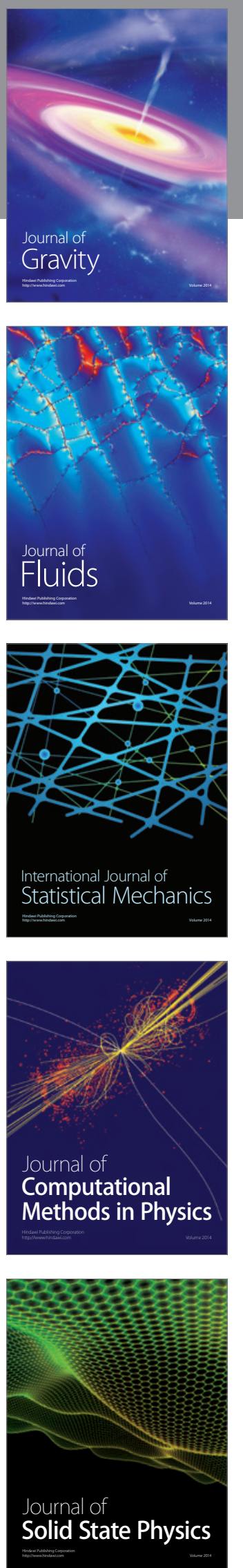

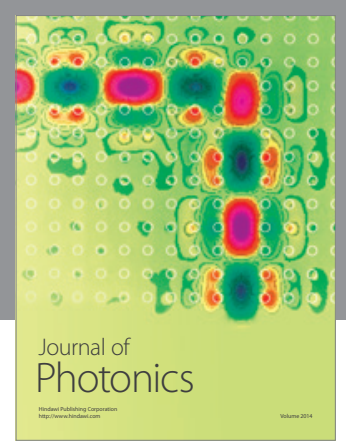

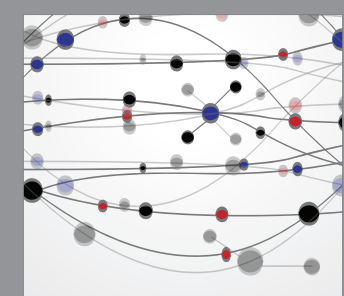

The Scientific World Journal
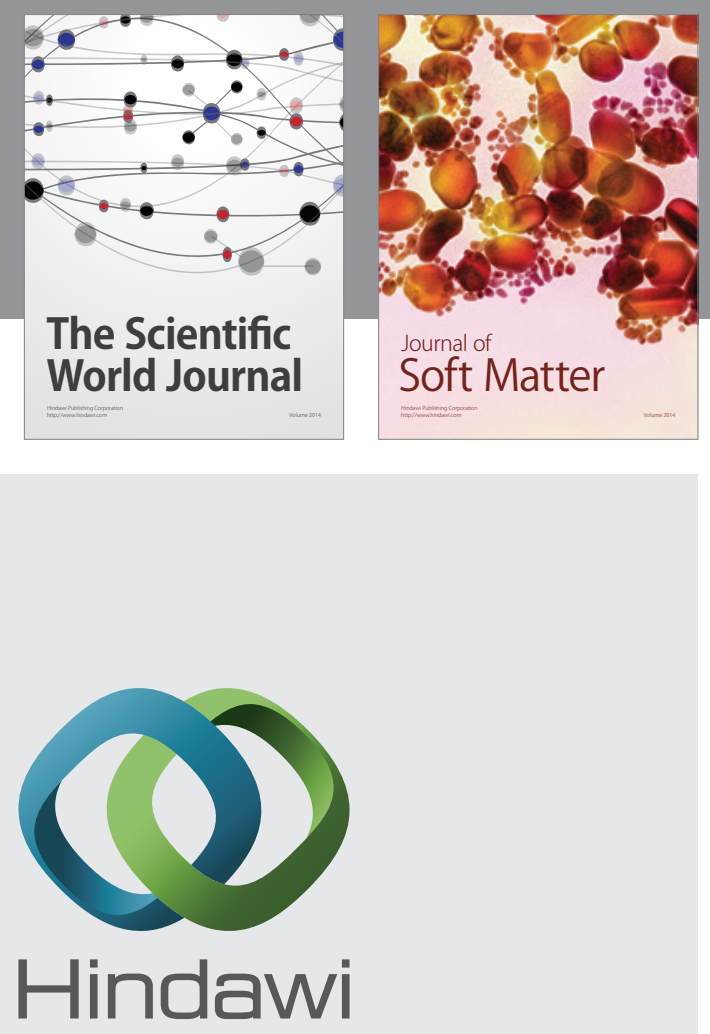

Submit your manuscripts at

http://www.hindawi.com
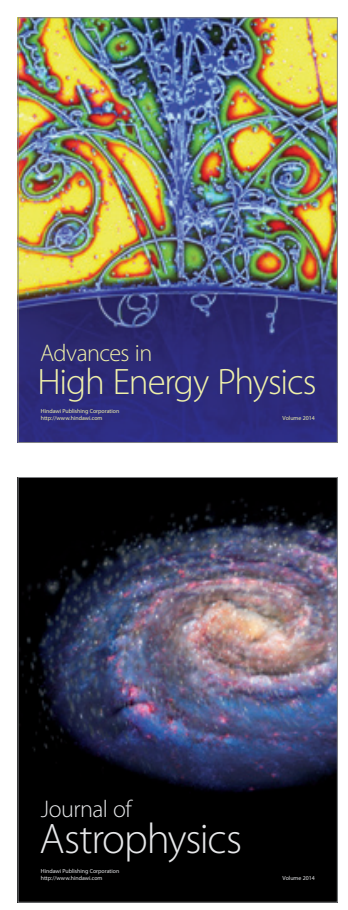
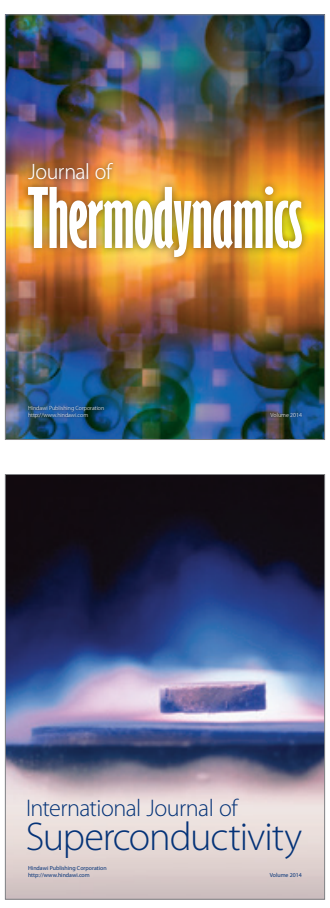
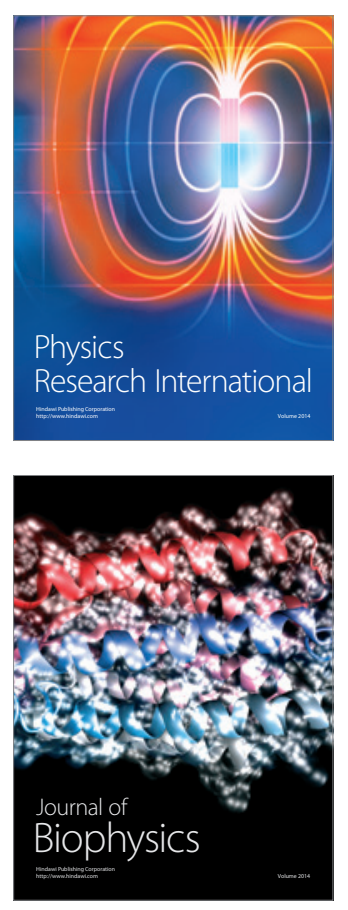
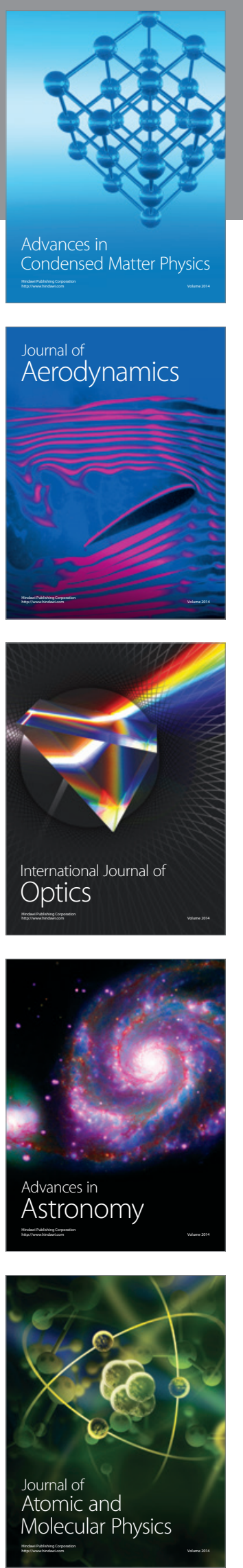